\title{
Fluticasone propionate compared with budesonide: double-blind trial in asthmatic children using powder devices at a dosage of $400 \mu$ fredey-1
}

\author{
J.C.M. Hoekx*, G. Hedlin**, W. Pedersen+, \\ K. Hollingworth\#, J. Efthimiou\# \\ R. Sorva ${ }^{++}$ \\ K. Hollingworth, J. Efthimiout
}

Fluticasone propionate compared with budesonide: a double-blind trial in asthmatic children using powder devices at a dosage of $400 \mathrm{mg} \cdot d a y^{-1}$. J.C.M. Hoekx, G. Hedlin, W. Pedersen, R. Sorva, K. Hollingworth, J. Efthimiou. @ERS Journals Ltd 1996.

ABSTRACT: The aim of this study was to compare fluticasone propionate (FP) with budesonide (BUD) at a dose of $400 \mu \mathrm{g} \cdot \mathrm{day}^{-1}$ in the treatment of children with asthma. Two hundred and twenty nine children with mild-to-moderate asthma, currently receiving $200-400 \mu \mathrm{g} \cdot \mathrm{day}^{-1}$ of inhaled corticosteroid, were randomized to receive either $400 \mu \mathrm{g} \cdot \mathrm{day}^{-1}$ of $\mathrm{FP}$ from the DiskhalerTM (registered trade mark of the Glaxo Group of Companies) or $400 \mu{\mathrm{g} \cdot d a y^{-1} \text { of BUD from the Turbuhaler }}^{\mathrm{TM}}$ (registered trade mark of Astra Pharmaceuticals Ltd) for 8 weeks, in a parallelgroup, double-blind, double-dummy study. Primary efficacy was assessed by measurement of daily peak expiratory flow (PEF). In addition, pulmonary function tests were performed at each clinic visit and a self-administered patient-centred questionnaire was completed by one parent of each patient at the start and end of study treatment.

Mean morning PEF increased following treatment both with FP and BUD, but was significantly higher following treatment with FP during Weeks $1-4(p=0.015)$ and Weeks 1-8 $(p=0.019)$. Similar results were found for mean evening PEF and percentage predicted morning and evening PEF. Children receiving FP experienced significantly less disruption in their physical activities (i.e. sports, games) because of their asthma compared to children treated with BUD $(p=0.03)$. Mean cortisol levels increased in both groups, but the increase was significantly higher in the FP group at 4 weeks $(p=0.022)$. Serum and urine markers of bone formation and resorption changed very little and showed no consistent pattern of change.

Fluticasone propionate at a dosage of $400 \mu \mathrm{g} \cdot \mathrm{day}^{-1}$ from the Diskhaler ${ }^{\mathrm{TM}}$ provided a more rapid and greater improvement in lung function in children with mild-to-moderate asthma than BUD $400 \mu$ day $^{-1}$ from the Turbuhaler ${ }^{\mathrm{TM}}$. Both treatments were well-tolerated, with a similar safety profile.

Eur Respir J., 1996, 9, 2263-2272.

\begin{abstract}
*Dept of Paediatrics, Groene Hart Ziekenhuis, Gouda, The Netherlands. **Dept of Paediatrics, Karolinska Institutet, Huddinge, Sweden. +Paediatric Dept, Centralsygehuseet Hillerod, Hillerod, Denmark. ${ }^{++}$Dept of Allergic Diseases, Helsinki University Central Hospital, Helsinki, Finland. \#Dept of Respiratory Medicine, Glaxo Wellcome Research and Development Ltd, U.K.
\end{abstract}

Correspondence: K. Hollingworth

Glaxo Wellcome Research and Development Greenford Road

Greenford

Middlesex UB6 OHE

UK

Keywords: Asthma

budesonide

fluticasone propionate

paediatric

powder device

Received: August 81995

Accepted after revision July 231996
Early use of inhaled anti-inflammatory treatment is widely recognized as being of key importance in the treatment of asthma, both in adults and children [1-3] and inhaled corticosteroids are considered the most effective anti-inflammatory agents available [2, 4]. At high doses, the systemic absorption of inhaled corticosteroids may carry a risk of side-effects in some patients [5]. These may include suppression of the hypothalamic-pituitary-adrenal (HPA) axis, demineralization of bone and growth retardation, all of which are particularly undesirable in growing children. It is, therefore, important for inhaled corticosteroids to have a high local potency coupled with a low systemic bioavailability, in order to have an acceptable therapeutic ratio for use in children.

Beclomethasone dipropionate (BDP) and budesonide (BUD) are inhaled corticosteroids, already widely-used in the treatment of asthma. Previous clinical studies in children have shown no clear advantage in terms of efficiency for either steroid [6-8]. However, several clinicopharmacological studies have suggested that BUD has a more favourable antiasthma to systemic glucocorticoid activity ratio than BDP, and BUD may be preferred where high doses of inhaled corticosteroids are needed to control asthma [9]. Pedersen and Fugslang [10] showed that, in asthmatic children, high-dose inhaled BDP resulted in lower urine cortisol excretion than high-dose BUD, the difference being most pronounced in children treated with doses of 1,000-1,200 $\mu \mathrm{g}$ daily. At standard doses of BDP and BUD (100-400 $\mu \mathrm{g}$ b.i.d.) other authors have shown little difference in effects on adrenal function in asthmatic children [7, 8, 11].

Fluticasone propionate (FP) is a new, topically active corticosteroid, which has been shown to have an improved therapeutic ratio in adults [12]. FP has negligible systemic availability from the gut due to a combination of poor gastrointestinal absorption and extensive first pass hepatic metabolism to inactive metabolites [13]. Therefore, 
although the majority of a dose of inhaled corticosteroid is swallowed (approximately 80\%), for FP almost none of this portion enters the systemic circulation. In contrast, BUD has an oral bioavailability of approximately $13 \%$ [14]. In preclinical and volunteer studies, FP has been shown to have a greater anti-inflammatory activity at a given microgram dose than the established corticosteroids [15]. Clinical studies have borne this out, showing that FP $200 \mu \mathrm{g} \cdot$ day $^{-1}$, is at least as effective as BDP, $400 \mu \mathrm{g} \cdot \mathrm{day}^{-1}$, in mild-to-moderate asthma in children [16].

FP may be administered by metered-dose inhaler (MDI) or as a powder via a dose-protected, breath-activated Diskhaler ${ }^{\mathrm{TM}}$ (registered trade mark of the Glaxo Group of Companies). The clinical efficacy and safety of FP administered by MDI or Diskhaler have been shown to be equivalent at doses of $200 \mu \mathrm{g} \cdot$ day $^{-1}$ [17], and $500 \mu \mathrm{g} \cdot \mathrm{day}^{-1}[18]$.

BUD may also be administered by MDI or as a powder via the TurbuhalerTM (registered trade mark of Astra Pharmaceuticals Ltd). Recently it has been reported that children receiving half the dose of BUD from the Turbuhaler compared to the MDI plus Nebuhaler ${ }^{\mathrm{TM}}$ (registered trade mark of Astra Pharmaceuticals Ltd), showed no difference in their asthma control, implying that BUD is delivered more efficiently to the lungs via the Turbuhaler [19]. However, White et al. [20] showed no difference between the Turbuhaler and the MDI plus Nebuhaler with respect to the delivery of BUD to the airways. Selroos and Holme [21] also showed no difference in efficacy between BDP, at a dose of $500 \mu \mathrm{g}$ b.i.d. delivered via the MDI plus Volumatic spacer, and BUD, $600 \mu \mathrm{g}$ b.i.d. delivered via the Turbuhaler. They did show, however, that mean serum cortisol and mean urinary cortisol excretion were significantly higher following treatment with BDP compared with BUD consistent with greater systemic absorption from the latter.

Comparisons of the Turbuhaler and Diskhaler devices have shown that these devices achieved similar clinical efficacy for delivering both beta-agonists [22] and corticosteroids [23]. HARVEY and WiLliams [24], however, in an open study showed that the Turbuhaler provided more effective bronchodilatation than the Diskhaler and the MDI.

In adults, there have been several comparative studies of FP and BUD using both powder and MDI formulations. FP, $200 \mu \mathrm{g} \cdot \mathrm{day}^{-1}$ via the Diskhaler, was shown to be as effective in terms of lung function improvement and more effective in terms of symptom control and relief bronchodilator use than BUD, $400 \mu \mathrm{g} \cdot \mathrm{day}^{-1}$ via the Turbuhaler [25]. In another study using these powder devices, FP $400 \mu \mathrm{g} \cdot \mathrm{day}^{-1}$ resulted in a significantly greater increase in mean morning PEF than did BUD $800 \mu \mathrm{g} \cdot$ day $^{-1}$ in mild-to-moderate asthmatics [26]. Mean serum cortisol levels were not affected in either study. In addition, in severe asthma, FP 1,000 $\mu \mathrm{g} \cdot \mathrm{day}^{-1}$ and FP 2,000 $\mu \mathrm{g} \cdot$ day $^{-1}$ were both shown to be significantly more effective than BUD $1600 \mu \mathrm{g} \cdot \mathrm{day}^{-1}$ [27]. One study in children comparing FP, $200 \mu \mathrm{g} \cdot \mathrm{day}^{-1}$ administered by a multidose powder inhaler, with BUD 400 $\mu \mathrm{g} \cdot \mathrm{day}^{-1}$ administered via the Turbuhaler, showed a difference in mean morning percentage predicted PEF in favour of FP after 4 weeks of treatment [28].

We present the results of the first double-blind comparison made between FP administered by Diskhaler and BUD administered by Turbuhaler to treat asthma in children. The same nominal dose of each product was used $\left(400 \mu \mathrm{g} \cdot \mathrm{day}^{-1}\right)$ and the primary objective was to compare their efficacy and effects on serum cortisol and serum and urinary indices of bone metabolism.

\section{Methods}

\section{Patients}

A total of 285 children with asthma were recruited at 22 centres in four countries. All were out-patients, who were already treated with inhaled corticosteroids at a prescribed dose of $200-400 \mu \mathrm{g} \cdot \mathrm{day}^{-1}$ and were using $\beta_{2}$-agonists as required. Two hundred and twenty nine prepubescent patients of mean age 8 yrs (range 4-13 yrs) entered the randomized phase of the study: 119 received FP, $400 \mu \mathrm{g} \cdot$ day $^{-1}$ by Diskhaler, and 110 received BUD, $400 \mu \mathrm{g} \cdot \mathrm{day}^{-1}$ by Turbuhaler. In the 2 week runin period preceding the randomized phase of the study, none of the 229 patients changed the medication they were using for asthma and all were required to demonstrate two of the following four criteria: daytime or night-time symptoms on four out of seven consecutive days; wakening during the night or early morning on one or more occasions; peak expiratory flow (PEF) of $\leq 75 \%$ of predicted value on four out of seven days; or at least $15 \%$ reversibility of the forced expiratory volume in one second (FEV1) or PEF in response to a $\beta_{2^{-}}$ agonist.

Patients were excluded: if they had received oral or parenteral corticosteroids during the 3 months prior to the run-in period; if they were unable to use the Diskhaler or the Turbuhaler device; if they were unable to use the mini-Wright ${ }^{\mathrm{TM}}$ (registered trade mark of Clement Clarke International Ltd) peak flow meter with or without parental help; and if they had suffered infection, seasonal allergy or any other disease likely to affect their asthma during the trial. Patients were also excluded if they had any known or suspected hypersensitivity to corticosteroids, and if they had received any other investigational drug within the previous month.

Regulatory and Ethics Committee approval was obtained prior to the start of the study. Written informed consent was obtained from a parent or guardian of each patient before entry into the study. The study was conducted in accordance with the declaration of Helsinki (Hong Kong amendment, 1989).

\section{Protocol}

This was a multicentre, double-blind, double-dummy, randomized, parallel-group study. During a 2 week runin period, patients continued to take their regular inhaled steroid and any other regular asthma therapy at a constant dose. They were issued with an inhaled $\beta_{2}$-agonist bronchodilator for use as required for the relief of symptoms. Patients meeting the inclusion criteria at the end of the run-in period were randomly assigned to receive treatment for 8 weeks either with $\mathrm{FP}, 400 \mu \mathrm{g} \cdot \mathrm{day}^{-1}$ by Diskhaler (as two puffs of $100 \mu \mathrm{g}$ b.i.d.) plus one puff twice daily from a placebo Turbuhaler, or BUD 
$400 \mu \mathrm{g} \cdot \mathrm{day}^{-1}$ by Turbuhaler (as one puff of $200 \mu \mathrm{g}$ b.i.d.) plus two puffs b.i.d. from a placebo Diskhaler. Treatment randomizations were achieved using a computerized scheme written in Fortran called "Patient Allocation for Clinical Trials" (PACT). The study treatments replaced their usual inhaled corticosteroid therapy. Patients continued to take their $\beta_{2}$-agonist as required. At the end of 8 weeks of randomized treatment, there was a 2 week follow-up period, during which time the patients were prescribed medication as deemed necessary by the investigator.

Efficacy assessments were based on daily measurements recorded in a diary card by the patients with their parents, and on pulmonary function tests performed at clinic visits at the end of the run-in period (baseline), after 2, 4 and 8 weeks of randomised treatment, and at the follow-up visit.

The patients measured PEF in the morning (07:00 to 08:00 h) and evening (19:00 to 20:00 h) with a miniWright peak flow meter and their parents recorded the results on the diary cards. Patients also recorded daytime and night-time asthma scores and an activity score, and noted any use of rescue medication or changes in use of other asthma medication. At clinic visits, PEF and/or FEV1 (highest of three in each case) were recorded. Although compliance was not formally monitored during the trial, patients were specifically asked a question at each clinic visit on their medication use between visits.

Patient-centred assessment. One parent of each patient completed a self-administered patient-centred assessment at the start and end of the 8 week treatment period. The seven item questionnaire was designed to evaluate the impact of the child's asthma on usual physical and social activities (i.e sports, games, playing with or visiting friends), sleep disturbance and days missed from schoolwork for the child and parent during the 2 months prior to each visit. The questions are listed in Appendix 1.

Adverse events. All adverse events were recorded, whether serious or minor and irrespective of their causality. Serious adverse events were defined as: death; lifethreatening events; disabling or incapacitating events; events which required or prolonged hospitalization; a resulting congenital abnormality; cancer; drug overdose; and any serious laboratory abnormality that was associated with clinical signs or symptoms.

\section{Laboratory evaluations}

Venous blood samples were collected during the clinic visits at baseline and after 4 and 8 weeks of treatment for the evaluation of haematology and biochemical parameters, and serum cortisol. Where possible, samples were taken from overnight fasted patients between 08:00 and 10:00 hours. At the baseline visit and at the end of 8 weeks of treatment, a small sample of serum was frozen for the future determination of the following bone markers: osteocalcin and procollagen type I carboxyterminal peptide (PICP) (markers of bone formation); and type-1 collagen carboxyterminal telopeptide (ICTP) (a marker of bone resorption). A $2 \mathrm{~h}$ urine collection was also made at baseline and after 8 weeks of treatment. A dipstick analysis was performed in the clinic, to determine the presence or absence of protein, blood or glucose. The urine sample was then frozen for the future determination of hydroxyproline corrected for creatinine, a marker of bone resorption.

The PICP assay was carried out using a competitive immunoassay, double antibody technique (Orion Diagnostica. Finland). One hundred millilitres of sample was mixed with $200 \mathrm{~mL}$ of PICP antiserum and $200 \mathrm{~mL}$ of $\mathrm{I}^{125}$-labelled PICP. After a $2 \mathrm{~h}$ incubation at $37^{\circ} \mathrm{C}$, separation reagent (second antibody covalently bound to solid particles) was added and the tubes were allowed to stand for a short while before centrifugation. The supernatant was discarded and the sediment counted in a gamma counter. At a concentration of $137 \mathrm{mg} \cdot \mathrm{L}^{-1}$, the between batch coefficient of variation $(\mathrm{CoV})$ was found to be $3.7 \%$ (A. Marcham, Biochemical Markers of Bone Disease, MSc thesis, London University, UK, 1993).

The ICTP assay (Orion Diagnostica, Finland) was carried out as outlined for the PICP assay, except that $\mathrm{I}^{125}$ ICTP was the tracer, and the separation reagent comprised polyethylene glycol (PEG) in phosphate-buffered saline (PBS) buffer, containing goat anti-rabbit gamma globulin. At a concentration of $6.2 \mathrm{mg} \cdot \mathrm{L}^{-1}$, the between batch CoV was $5.3 \%$ (A. Marcham, Biochemical Markers of Bone Disease, MSc thesis, London University, UK, 1993).

The osteocalcin assay was also based on a competitive radioimmunoassay, double antibody technique (CIS bio international, France). A $50 \mathrm{~mL}$ sample was added to $200 \mathrm{~mL}$ of $\mathrm{I}^{125}$-labelled osteocalcin and $100 \mathrm{~mL}$ of anti-osteocalcin (rabbit antibovine) second antibody. The solution was mixed gently using a vortex type mixer and incubated for $20-24 \mathrm{~h}$ at $2-8^{\circ} \mathrm{C}$. After centrifugation, the sediment was counted in a gamma counter. At a concentration of $3.8 \mathrm{mg} \cdot \mathrm{mL}^{-1}$, the between batch $\mathrm{CoV}$ was $6.6 \%$ (A. Marcham, Biochemical Markers of Bone Disease, MSc thesis, London University, UK, 1993).

The urinary hydroxyproline assay measured both free and peptide-bound hydroxyproline in the urine, i.e. total urinary hydroxyproline. Urine samples were first hydrolysed with hydrochloric acid to release peptide-bound hydroxyproline. The total hydroxyproline was then reacted with phenylisothiocyanate to form a phenylthiocarbonate. Phenylthiocarbonates formed with hydroxyproline and other amino acids were then separated using reversed phase high performance liquid chromatography (RPHPLC), and quantitated by detection at $254 \mathrm{~nm}$. Results were expressed as a hydroxyproline/creatinine ratio. The between batch $\mathrm{CoV}$ was $6.5 \%$ (West Middlesex University Hospital, London, UK).

The serum cortisol assay was carried out using a coated tube method radioimmunoassay. The between batch CoV was $7.0 \%$ (West Middlesex University Hospital, London, UK).

\section{Analysis}

Statistical analyses were carried out using SAS (version 6.08). All tests were carried out at the two-sided 
5\% level of significance. Baseline PEF was established by taking the mean of available data for the second week of the run-in period. For the treatment period, diary card PEF data were analysed for Weeks 1-4, Weeks 5-8 and Weeks $1-8$ of treatment. The mean morning and evening PEFs were calculated over each period for each patient, and were expressed both as absolute values and as a percentage of the predicted value. Predicted PEF was calculated using the formula: predicted PEF $=524.28 \times$ Height -425.5714 , where $\mathrm{PEF}$ is measured in $\mathrm{L} \cdot \mathrm{min}^{-1}$ and height is measured in meters [29]. For clinic lung function data, Predicted PEF was calculated using the same formula; predicted FEV1 was calculated using the formula: predicted FEV1 $=0.836 \times$ Height $^{2.8}$, where FEV1 is measured in litres and height in metres [29].

Changes from baseline in diary card PEFs and changes from baseline in clinic lung function values together with plasma cortisol concentrations (which were previously log-transformed) were analysed by analysis of covariance, adjusting for baseline, age, sex and country. Centres were grouped by country for the analysis to avoid the effects of too few patients in any one centre. Frequency distributions were calculated for median daytime symptom score for each treatment, and the difference between treatments was assessed using the Wilcoxon Rank Sum Test, and the Hodges-Lehmann Test [30]. Country and gender effects were explored using the Van Elteren Test [31]. Similar methods of analysis were applied to symptom scores, activity scores, number of symptom-free days, use of rescue medication and bone markers. The frequency of the most common adverse events (incidence $>5 \%$ ) was compared between treatments using Fisher's exact test (twice onesided).

Nonparametric analysis of variance (ANOVA) was used to test differences between FP and BUD groups for days missed from school/work. The Wilcoxon Rank Sum Test was used to analyse differences between FP and BUD for the impact on sleep disturbance and usual activities.

\section{Results}

\section{Patients}

Patient characteristics at baseline are shown in table 1. One hundred and nineteen patients received FP and 110 received BUD. The two treatment groups were well-matched with respect to demographic characteristics, history of asthma, concurrent medication, mean daily dose of inhaled corticosteroid at entry to study and baseline pulmonary function. Notably, the baseline mean percentage predicted morning PEF in each group was nearly $100 \%$ (mean of $98 \%$ in the FP group and $97 \%$ in the BUD group). No patients were withdrawn due to poor compliance in either treatment group.

\section{Efficacy}

Daily morning and evening PEFs. A summary of the principal results is given in table 2 , which shows that
Table 1. - Patient characteristics at baseline

\begin{tabular}{|c|c|c|c|}
\hline Characteristic & \multicolumn{2}{|c|}{$\begin{array}{c}\text { FP } \\
400 \mu \mathrm{g} \cdot \mathrm{day}^{-1}\end{array}$} & $\begin{array}{c}\text { BUD } \\
400 \mu \mathrm{g} \cdot \text { day }^{-1}\end{array}$ \\
\hline Patients $n$ & 119 & & 110 \\
\hline Sex $n$ & & & \\
\hline Males & 81 & $(68)$ & $75(68)$ \\
\hline Females & 38 & (32) & $35(32)$ \\
\hline \multicolumn{4}{|l|}{ Age $n$} \\
\hline $4-6$ yrs & 29 & (24) & $27(25)$ \\
\hline 7-9 yrs & 58 & (49) & $46(42)$ \\
\hline $10-12$ yrs & 31 & (26) & $37(34)$ \\
\hline$>12$ yrs & 1 & $(<1)$ & 0 \\
\hline Age range yrs & $5-13$ & & $4-12$ \\
\hline \multicolumn{4}{|l|}{ Duration of asthma $n$} \\
\hline$<1 \mathrm{yr}$ & 4 & (3) & 2 (2) \\
\hline $1-5$ yrs & 75 & (63) & $61(55)$ \\
\hline $6-10$ yrs & 39 & (33) & $42(38)$ \\
\hline$>10$ yrs & 1 & $(<1)$ & $5 \quad(5)$ \\
\hline \multicolumn{4}{|l|}{ History of atopy $n$} \\
\hline Yes & 96 & $(81)$ & $92(84)$ \\
\hline No & 22 & (18) & $16(14)$ \\
\hline Not known & 1 & $(<1)$ & $2(2)$ \\
\hline \multicolumn{4}{|c|}{ Concurrent asthma medications $\mathrm{n}$} \\
\hline $\begin{array}{l}\text { Inhaled long-acting } \\
\beta_{2} \text {-agonists }\end{array}$ & 2 & (2) & $1(<1)$ \\
\hline Sodium cromoglycate & 10 & (8) & $14(13)$ \\
\hline Methylxanthines & 3 & (3) & $1(<1)$ \\
\hline Other asthma medications & $2 *$ & (2) & 0 \\
\hline \multicolumn{4}{|l|}{ Mean PEF at end of run-in } \\
\hline Morning L·min ${ }^{-1}$ & 256 & & 259 \\
\hline$\%$ pred & 98 & & 97 \\
\hline Evening $\mathrm{L} \cdot \mathrm{min}^{-1}$ & 264 & & 266 \\
\hline$\%$ pred & 101 & & 99 \\
\hline $\begin{array}{l}\text { Mean daily dose of inhaled } \\
\text { corticosteroid at entry } \mu \mathrm{g}\end{array}$ & 355 & & 351 \\
\hline
\end{tabular}

Values in parentheses are percentages. FP: fluticasone propionate; BUD: budesonide; PEF: peak expiratory flow; \% pred: percentage of predicted value. $*$ : one necrodomil sodium and one not specified.

the improvement in adjusted mean morning PEF was significantly higher with FP than with BUD during Weeks 1-8 and Weeks 1-4 ( $\mathrm{p}=0.015)$; there were similar differences during Weeks 5-8 $(\mathrm{p}=0.056)$. There were no statistically significant interactions including age, which suggests that the treatment effect was the same for all ages. Adjusted mean evening PEF was also higher during Weeks 1-8 with FP than with BUD, but the difference did not reach statistical significance (table 2), whereas the difference at Weeks 1-4 was statistically significant $(\mathrm{p}=0.026)$.

The mean percentage of predicted PEF increased during both treatments. There was a statistically significant difference between treatments in favour of FP in terms of the adjusted mean percentage of predicted PEFs, both morning and evening, for Weeks 1-8 (table 2). The same was true for morning data from Weeks $1-4(p=0.004)$ and 5-8 $(\mathrm{p}=0.040)$ and for evening data from Weeks $1-4(\mathrm{p}=0.005)$ but not weeks 5-8 $(\mathrm{p}=0.077)$.

Figure 1 shows the proportion of patients at each week during treatment whose percentage of predicted morning PEF increased from baseline by at least $10 \%$. Throughout the treatment period, there were more patients in the FP group than in the BUD group with an improvement of $\geq 10 \%$. The difference between groups was statistically 
Table 2. - Daily morning and evening PEFs

\begin{tabular}{|c|c|c|c|c|c|c|c|c|}
\hline \multirow[t]{2}{*}{ Parameter } & \multicolumn{3}{|c|}{$\begin{array}{c}\text { FP } \\
(\mathrm{n}=119)\end{array}$} & \multicolumn{3}{|c|}{$\begin{array}{c}\text { BUD } \\
(\mathrm{n}=110)\end{array}$} & \multicolumn{2}{|c|}{$\begin{array}{l}\text { Difference between } \\
\text { adjusted means }\end{array}$} \\
\hline & $\begin{array}{l}\text { Mean at } \\
\text { baseline }\end{array}$ & $\begin{array}{c}\text { Mean at } \\
\text { Weeks 1-8 }\end{array}$ & $\begin{array}{c}\text { Adjusted } \\
\text { mean } \\
\text { Weeks 1-8* }\end{array}$ & $\begin{array}{l}\text { Mean at } \\
\text { baseline }\end{array}$ & $\begin{array}{c}\text { Mean at } \\
\text { Weeks 1-8 }\end{array}$ & $\begin{array}{c}\text { Adjusted } \\
\text { mean } \\
\text { Weeks } 1-8^{*}\end{array}$ & $\begin{array}{l}\text { Difference } \\
(95 \% \mathrm{CI})\end{array}$ & p-value \\
\hline \multicolumn{9}{|c|}{ Morning PEF } \\
\hline $\mathrm{L} \cdot \mathrm{min}^{-1}$ & 256 & 274 & 274 & 259 & 270 & 267 & $7(1-14)$ & 0.019 \\
\hline$\%$ pred & 98 & 105 & 104 & 97 & 100 & 101 & $3(1-5)$ & 0.007 \\
\hline \multicolumn{9}{|c|}{ Evening PEF } \\
\hline $\mathrm{L} \cdot \mathrm{min}^{-1}$ & 264 & 278 & 279 & 266 & 276 & 273 & $5(0-11)$ & 0.054 \\
\hline$\%$ pred & 101 & 107 & 106 & 99 & 103 & 103 & $2(0-4)$ & 0.017 \\
\hline
\end{tabular}

*: adjusted for differences in baseline, gender, age and country. 95\% CI: 95\% confidence interval. For further definitions see legend to table 1 .

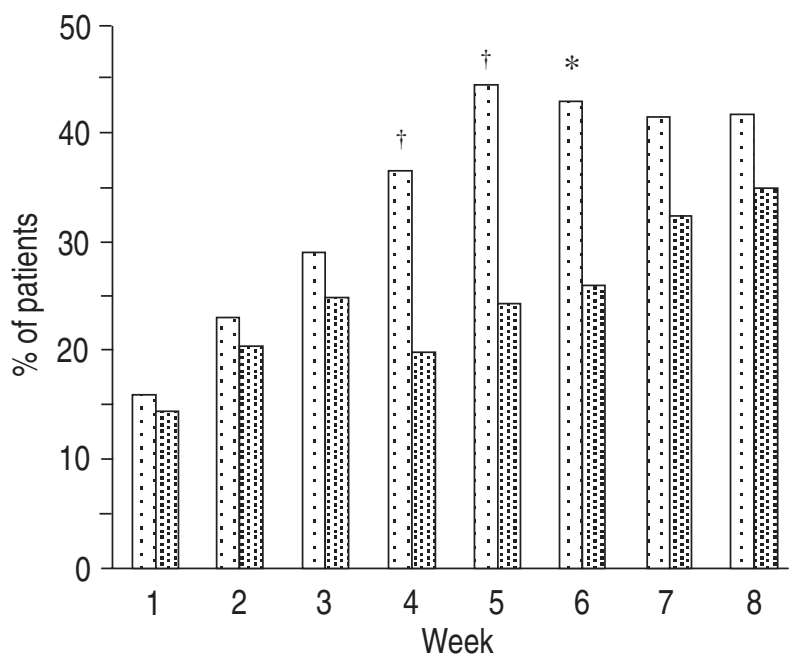

Fig. 1. - Proportion (\%) of patients at each week during treatment whose percentage predicted morning PEF increased from baseline by at least $10 \%$. $\because \cdot$ : fluticasone propionate, $400 \mu \mathrm{g} \cdot$ day $^{-1}$; budesonide (BUD), $400 \mu \mathrm{g} \cdot$ day $^{-1}{ }^{*} *: \mathrm{p}<0.05,{ }^{\dagger}: \mathrm{p}<0.005$, compared to BUD group.

significant after 4 and $5(\mathrm{p}<0.005)$, as well as $6(\mathrm{p}<0.05)$ weeks of treatment, but not after 8 weeks.

The maximum change in mean morning PEF was reached by Week 5 in the FP group compared to week 8 on BUD. Similarly, the maximum change in mean evening PEF was reached by weeks 4 and 8 , respectively.

Symptom scores and use of rescue medication. The percentage of symptom-free days and nights and the percentage of days with normal activity all increased from baseline in both groups, with no statistically significant difference between treatments. The median percentage of symptom-free days reached $100 \%$ by week 4 with FP, whereas it did not reach $100 \%$ until week 7 with BUD. The distribution of mean symptom scores during weeks 1-8 was similar in both treatment groups. More than $70 \%$ of patients in both groups had a median symptom score of zero (asymptomatic), and approximately $60 \%$ of patients had a median activity score of zero (unrestricted) during both treatments.

At baseline, the median percentage of days on which no rescue medication was needed was zero in both groups.
The median percentage of rescue-free days increased with both treatments; the mean over weeks 1-8 was 43 for FP and 44 for BUD.

Clinic measurements of lung function. PEF and FEV1 increased steadily in both groups during the study. There were no statistically significant differences between the treatments. Mean percentage of predicted PEF in the FP group increased from $98 \%$ at baseline to $104 \%$ at 8 weeks; corresponding values in the BUD group were 96 and $100 \%$, respectively. Mean percentage of predicted FEV1 in the FP group increased from $88 \%$ at baseline to $92 \%$ at 8 weeks; in the BUD group the increase was from 87 to $89 \%$.

Patient-centred assessment. Children receiving both FP and BUD experienced less disruption in their physical activities because of their asthma after 8 weeks of treatment. This improvement was significantly greater in the FP group compared with BUD $(\mathrm{p}=0.03)$ (table 3$)$. Sleep disturbance also tended to occur less often for the child receiving FP compared to BUD but the differences were not statistically significant. Very few days were missed from school for children (median 0 , range 0-7 days over the 2 weeks prior to each assessment) or work for parents (median 0, range 0-4 days) in the total

Table 3. - Patient-centred assessment: effect of FP and BUD on physical activities

\begin{tabular}{|c|c|c|c|}
\hline $\begin{array}{l}\text { Physical } \\
\text { activities* }\end{array}$ & $\begin{array}{c}\text { FP } \\
400 \mu \mathrm{g} \cdot \mathrm{day}^{-1} \\
(\mathrm{n}=100) \\
\%\end{array}$ & $\begin{array}{c}\text { BUD } \\
400 \mu \mathrm{g} \cdot \mathrm{day}^{-1} \\
(\mathrm{n}=91) \\
\%\end{array}$ & p-value \\
\hline \multicolumn{4}{|l|}{ Week 0} \\
\hline Often & 9 & 10 & 0.889 \\
\hline Sometimes & 43 & 46 & \\
\hline Rarely & 38 & 29 & \\
\hline Never & 10 & 15 & \\
\hline \multicolumn{4}{|l|}{ Week 8} \\
\hline Often & 4 & 7 & 0.031 \\
\hline Sometimes & 24 & 36 & \\
\hline Rarely & 37 & 34 & \\
\hline Never & 36 & 23 & \\
\hline
\end{tabular}

FP: fluticasone propionate; BUD: budesonide. *: actual question: In the past two months, how often has your child been prevented from doing or had to stop doing certain activities because of his or her asthma (e.g. sports, games with friends, visiting friends, etc.)? 
study population. There was no statistically significant difference between the treatment groups. It should be noted that $42 \%$ of parents answered the productivity questions as "not applicable" at the end of treatment as they were nonworking mothers.

\section{Safety}

Adverse events. Eight patients withdrew from the study after randomization, three because they did not meet the study entry criteria and five due to adverse events (two from the FP group and three from the BUD group). All adverse events leading to withdrawal were classified as "asthma and related events", except one due to allergic skin reaction (BUD group).

Two serious adverse events occurred during the study, one in each treatment group: one allergic skin reaction in the BUD group considered to be related to the study drug and leading to treatment cessation (above); and one case of cervical lymphadenitis in the FP group requiring hospitalization but considered to be unrelated to the study drug. Overall, the adverse event profile of the two treatments was similar, the most common adverse event type reported being asthma and related events (24\% of patients in the FP group, $25 \%$ in the BUD group). With FP and with BUD, respectively, the percentage of patients with adverse events during treatment was 63 and $69 \%$, and the percentage with drug-related adverse events was 9 and $14 \%$. The most common adverse events (incidence $\geq 5 \%$ ) are shown by treatment group in table 4 . There was no statistically significant difference between treatment groups in the incidence of any of these events. Pharmacologically predictable adverse events occurred with broadly comparable frequency during treatment with FP or BUD, respectively: oral candidiasis 3 and $<1 \%$; rash/skin eruption $<1$ and $<1 \%$; hoarseness 0 and 4\%; allergic skin reaction $<1$ and $5 \%$ (no statistically significant difference between treatment groups).

Vital signs. There were no clinically relevant changes in heart rate or blood pressure. The majority of patients had a small weight gain during the treatment period. Seven percent of patients on FP and $8 \%$ of those on BUD had a weight increase greater than $7 \%$ (predefined

Table 4. - Patients who had an adverse event with an incidence of $\geq 5 \%$ during treatment

\begin{tabular}{lrrrr}
\hline & \multicolumn{2}{c}{ FP } & \multicolumn{2}{c}{ BUD } \\
& \multicolumn{2}{c}{$400 \mu \mathrm{g} \cdot \mathrm{day}^{-1}$} & \multicolumn{2}{c}{$400 \mu \mathrm{g} \cdot \mathrm{day}^{-1}$} \\
& $\mathrm{n}=119)$ & \multicolumn{2}{c}{$(\mathrm{n}=110)$} \\
& 75 & 63 & 76 & 69 \\
\hline Patients with adverse event & 28 & 24 & 28 & 25 \\
Asthma and related events & 15 & 13 & 10 & 9 \\
Eye disorders & 14 & 12 & 16 & 15 \\
Upper respiratory tract infection & 13 & 11 & 13 & 12 \\
Rhinitis & 8 & 7 & 4 & 4 \\
Ear problems & 7 & 6 & 4 & 4 \\
Cough & 5 & 4 & 5 & 5 \\
Pyrexia & 5 & 4 & 5 & 5 \\
Sore throat & 3 & 3 & 8 & 7 \\
Headache & 3 & 3 & 6 & 5 \\
Influenza & 1 & $<1$ & 6 & 5 \\
Allergic skin reactions & &
\end{tabular}

FP: fluticasone propionate; BUD: budesonide. threshold). All changes were thought to be consistent with expected growth rates in this age group.

Laboratory evaluations. There were no clinically significant abnormalities in routine haematology or biochemistry measurements during the study.

Analysis of the changes in the geometric mean morning serum cortisol values, conducted only for patients with measurements both at baseline and at the relevant time-points, showed no evidence of HPA suppression. In fact, mean serum cortisol values rose during both treatments. The geometric mean value for patients on FP rose from $248 \mathrm{nmol} \cdot \mathrm{L}^{-1}$ (baseline) to $291 \mathrm{nmol} \cdot \mathrm{L}^{-1}$ (after 8 weeks of treatment) and the mean value for those on BUD rose from $214 \mathrm{nmol} \cdot \mathrm{L}^{-1}$ (baseline) to 246 $\mathrm{nmol} \cdot \mathrm{L}^{-1}$ (after 8 weeks of treatment). The FP:BUD ratio was calculated as the change in the mean cortisol value, from baseline to weeks 4 and 8 of treatment, during treatment with FP divided by the change during BUD treatment (taking into account differences in baseline values). The ratios were 1.13 after 4 weeks of treatment and 1.11 after 8 weeks of treatment, both in favour of FP and statistically significant at 4 weeks $(p=0.022)$ (table 5).

Bone markers. The median baseline values in each treatment group and the normal ranges of the serum markers of bone metabolism are shown in table 6. Baseline values in both treatment groups were within the normal range for all parameters. A normal range was not available for urinary hydroxyproline/creatinine ratio due to the variation in creatinine, related to body mass, seen in this age group.

Table 6 shows the median change from baseline in all markers of bone metabolism. The results were highly variable and showed no consistent pattern of change. With regard to markers of bone formation, osteocalcin barely changed during either treatment and PICP increased in both groups, with no statistically significant difference between treatments for either parameter. With regard to markers of bone resorption, there was no difference between treatments for urinary hydroxyproline: creatinine ratio, but ICTP levels fell slightly during treatment with BUD and increased slightly during treatment with FP. The PICP:ICTP ratio, an index of overall bone turnover, showed very little change from baseline and no significant difference between treatments. In addition, at the end of 8 weeks of treatment, the median of each serum bone marker remained within the normal range in both treatment groups.

Table 5. - Early morning serum cortisol concentrations

\begin{tabular}{lcccc}
\hline \multicolumn{5}{c}{$\begin{array}{c}\text { Serum cortisol concentration* } \\
\text { nmol·L-1 }\end{array}$} \\
& $\begin{array}{c}\text { FP } \\
400 \mathrm{~g} \cdot \mathrm{day}^{-1} \\
(\mathrm{n}=119)\end{array}$ & $\begin{array}{c}400 \mu \mathrm{H} \cdot \mathrm{day}^{-1} \\
(\mathrm{n}=110)\end{array}$ & RP/BUD & $\mathrm{p}$-value \\
\hline Baseline & 248 & 214 & & \\
4 weeks & 266 & 221 & 1.13 & 0.022 \\
8 weeks & 291 & 246 & 1.11 & 0.074 \\
\hline
\end{tabular}

FP: fluticasone propionate; BUD: budesonide; *: geometric mean value; **: taking into account differences in baseline, gender, age and country. 
Table 6. - Markers of bone metabolism at baseline and after treatment

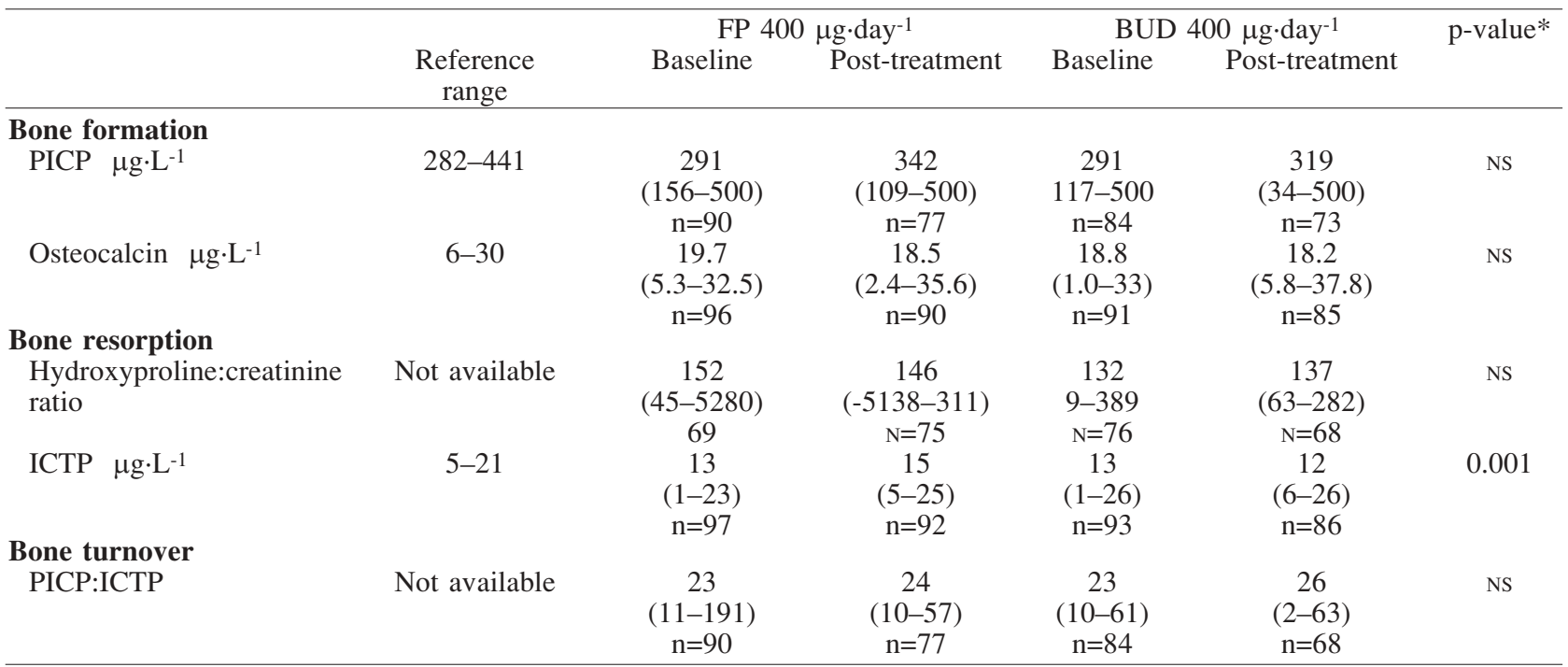

Values are median and range in parentheses. FP: fluticasone propionate; BUD: budesonide; PICP: procollagen type I carboxyterminal peptide; ICTP: type I carboxyterminal telopeptide; NS: no significant difference. *: comparing the change from baseline with FP $v s$ that with BUD.

\section{Discussion}

This double-blind study is the first comparing the powder formulations of FP and BUD, at a dose of 400 $\mu \mathrm{g} \cdot \mathrm{day}^{-1}$, in children with mild-to-moderate asthma. It should be emphasized that the doses used in this study were nominal and that differences in the drug delivery to the lungs from these different devices might also influence the clinical potency of these drugs. Unfortunately, lung deposition studies comparing the Turbuhaler and the Diskhaler have not been performed. BROwN et al. [22] found that these devices achieved similar clinical efficacy for delivery of beta-agonists. Petrie et al. [23] also found that the Turbuhaler and the Diskhaler resulted in similar clinical efficacy for delivering corticosteroids. However HaRveY and WiLliams [24] showed that the Turbuhaler provided more effective bronchodilatation than the Diskhaler and the MDI. The reason for using two different devices in this study is that powders are the preferred method of administration of corticosteroids in children, and this study set out to compare FP in its licensed powder system with BUD in its licensed powder system. In addition, it is not yet possible to put both of these molecules into either one of these powder devices.

During 8 weeks of treatment, FP provided a more rapid and greater improvement in morning and evening PEF than BUD. The relatively small improvements in lung function seen in this study highlight the difficulty of comparing inhaled steroids in a population of patients already receiving a moderate dose of inhaled steroid. Despite the small difference between treatments in the improvement in mean morning PEF, the additional benefit of FP in increasing the patients' social and physical activities suggests that this result may be of clinical value. The baseline percentage predicted PEF in both treatment groups was close to $100 \%$ leaving little room for improvement during the study. In addition, 57 (25\%) patients randomized into the study, did not demonstrate the level of symptoms required by the inclusion criteria in the protocol at the end of the run-in period. Therefore, although these patients were considered moderate asthmatics in terms of their corticosteroid requirements, their symptoms and their reduction in lung function at baseline were relatively mild. Despite this, $45 \%$ of patients on FP and $36 \%$ of patients on BUD showed an increase in percentage predicted PEF of $\geq 10 \%$ during the 8 week treatment period. At each weekly time-point, there were consistently more patients on FP than on BUD showing an increase of that magnitude. By week five, the increase in mean PEF in the FP group had plateaued, probably because there was no room to improve further. Hence, by week eight, there was no significant difference in the increase in mean PEF between the treatment groups. No patients were withdrawn from the study due to poor compliance, and it is most unlikely that these results were significantly influenced by compliance, as this would be expected to be similar, at whatever level, in both groups.

Asthma in children has been associated with disruption in physical activities, such as playing games, running and sports [32]. In this study, physical disruption was reported less in children receiving FP than in those treated with BUD. This difference may be associated with the greater improvement in PEF seen in the FP group. These results are similar to those reported by JUNIPER et al. [33], who showed a moderate correlation between the change in the response to the Asthma Quality of Life Questionnaire (AQLQ) and the change in spirometry in mild-to-moderate asthmatics. Very few children missed any days from school, reflecting the relatively well-controlled population studied. This was further confirmed by the few work days missed by parents. Much of the parent productivity data was unavailable due to a large percentage of nonworking mothers completing the questionnaire, suggesting that inappropriate questions were used for this group of parents.

There were no differences between the treatments with respect to the secondary efficacy parameters of clinic lung function measurements or symptom scores. 
This was not surprising in view of the patients' relatively well-controlled symptoms and lung function at entry to the study, leaving little room for improvement.

Adverse events in this study were mostly mild and predictable, indeed the majority related to exacerbations of asthma itself. The other most commonly reported events were related to eye disorders, upper respiratory tract infections and rhinitis. These were not unexpected, particularly as the period of study included the tree and grass pollen season. Only two serious events were reported during the study, and only one of these was considered to be treatment-related (allergic skin reaction with BUD).

The safety of inhaled steroids is still of prime concern to doctors prescribing to young asthmatics. Despite recent guidelines [3] advocating the use of inhaled steroids as important anti-inflammatory treatment, some doctors remain uncertain about their use. One of the main objectives of this study was to compare the safety of FP with BUD with respect to HPA-axis function and bone metabolism, as well as on the overall incidence of adverse events.

There was no evidence of HPA-axis suppression by either treatment and, in fact, mean serum cortisol levels increased for both treatment groups over the 8 week period. Seventy three percent of patients were receiving $400 \mu \mathrm{g} \cdot \mathrm{day}^{-1}$ of BUD or BDP immediately prior to entry to the study. The results suggest that some patients were already suppressed on entry to the study and that this diminished on the study medication. NICOLAIZIK et al. [34] also showed a significant HPA-axis suppression following $400 \mu \mathrm{g} \cdot \mathrm{day}^{-1}$ of BDP or BUD in a 2 week cross-over trial in children with asthma. However, other studies with inhaled BUD and BDP have found no evidence of HPA-axis suppression until doses exceeded 400 $\mu \mathrm{g} \cdot \mathrm{day}^{-1}$ [35-37]. In previous studies, inhaled FP up to $200 \mu \mathrm{g} \cdot \mathrm{day}^{-1}$ did not suppress serum cortisol levels during 6 weeks [38] or one year of treatment [39]. The measurement of morning serum cortisol is not an ideal method of assessing adrenal function due to diurnal variations in the measurement. It is generally agreed that the measurement of cortisol excretion in $24 \mathrm{~h}$ urine collections is more reliable but not practical in a multinational, paediatric trial.

The results of the bone marker analyses were highly variable, with no consistent pattern of change. However, there appeared to be little effect of either treatment on overall bone turnover. Both at the start and end of treatment, serum bone marker levels were within the normal range. The significance of changes in markers of bone formation and resorption in patients with asthma remains unclear, particularly in children, where the effects of normal growth on these indices is not well understood. The results of bone marker studies cited in the literature are varied. Sorva et al. [40] demonstrated a statistically significant decrease in osteocalcin and PICP levels following 1 month of treatment with BUD, at a dose of $800 \mu \mathrm{g} \cdot \mathrm{m}^{-2}$ daily. PRIFTIS et al. [41] showed a decrease in osteocalcin following BDP, $180-790 \mu \mathrm{g} \cdot \mathrm{m}^{-2}$ daily, but showed no effect on bone resorption or reduction in bone mineral content (median treatment period 11.5 months). Doull et al. [42] found no effect of 6 months of treatment with BDP $400 \mu \mathrm{g} \cdot \mathrm{day}^{-1}$, on osteocalcin or urinary hydroxyproline/creatinine ratio. Moreover, one study has shown that children with asthma have lower serum osteocalcin levels than normal control subjects without asthma, and that treatment with BDP (up to 800 $\mu \mathrm{g} \cdot \mathrm{day}^{-1}$ ) did not affect these values [43].

A recent study by WOLTHERS and PEDERSEN [44] found knemometry to be a more sensitive test than $24 \mathrm{~h}$ urine free cortisol excretion in assessing the systemic effects of corticosteroids in children. However, only specialized centres have the facilities to perform this measurement and, again, it would not be practical to assess this parameter in a multicentre trial. In a 2 week, singlecentre, cross-over trial investigating short-term lower leg growth by knemometry [45], FP, 200 and $400 \mu \mathrm{g} \cdot$ day $^{-1}$, and BUD, at $200 \mu \mathrm{g} \cdot \mathrm{day}^{-1}$ had no significant effect on lower leg growth rates compared with placebo. However, BUD, $400 \mu \mathrm{g} \cdot \mathrm{day}^{-1}$ resulted in a significant reduction in growth rates when compared with placebo. This study also investigated a range of markers of bone metabolism and showed no differences between any of the treatments. The authors concluded that dose for dose the systemic effects of FP and BUD are similar. It remains to be seen how these biochemical markers and short-term assessments of growth relate, if at all, to long-term changes in bone density and growth.

In conclusion, this study demonstrates that fluticas-

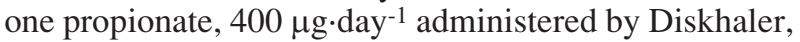
provides a more rapid and significantly greater improvement in lung function in children with mild-to-moderate asthma than the same dose of budesonide administered by Turbuhaler. In addition, both treatments were welltolerated, with no evidence of hypothalamic-pituitaryadrenal axis suppression or of any effect on overall bone turnover with either treatment, although serum cortisols were significantly higher during treatment with fluticasone propionate. As predicted from its pharmacological profile and confirmed in clinical studies in adults [12] and by the findings of this study, inhaled fluticasone propionate has a relatively high therapeutic ratio, making it particularly useful for the optimum maintenance treatment of asthma in children.

\section{Appendix 1: patient-centred assessment}

Section I:

1. If in employment, how many days off work have you had because of your child's asthma?

--in the last 2 months

--in the last 2 weeks

--not applicable

2. If your partner is in employment, how many days off work has your partner had because of your child's asthma?

--in the last 2 months

--in the last 2 weeks

--not applicable

days

days

3. During the past 2 months, have your social activities been limited because of your child's asthma? --often

--sometimes

--rarely

--never 
4. During the past 2 months, how often have you been disturbed during the night by your child's asthma?

$$
\begin{aligned}
& \text {--often } \\
& \text {--sometimes } \\
& \text {--rarely } \\
& \text {--never }
\end{aligned}
$$

\section{Section II:}

1. If your child attends school, how many days off school has your child had because of his/her asthma?

--in the last 2 months

--in the last 2 weeks days --not applicable

2. In the last 2 months, how often has your child's sleep been disturbed because of his/her asthma? --often

--sometimes

--rarely

--never

3. During the pat 2 months, how often has your child been prevented from doing or had to stop doing certain activities because of his/her asthma (e.g. sports, games with friends, visiting friends, etc.)? --often

--sometimes

--rarely

--never

Acknowledgements: The authors wish to thank the following investigators who participated in this study: T. Berg, L. Browaldh, P. Gustafsson, J.A. Jonsson, C. Moller, I.L. Strannegard (Sweden) J.H. Scheewe, J.G. Brinkman, J.J. Gosen (The Netherlands); K.A. Lorentzen, N. Hyldebrandt, K.K. Ibsen, B. Marner, C. Vrang (Denmark); P. Syvanen, V. Vahasarja, O. Wanne, B. Gustafsson, M. Finnila (Finland). They would also like to thank R. Lam (Glaxo Wellcome, Canada) for his contribution to the data analysis.

\section{References}

1. British Thoracic Society. Guidelines for management of asthma in adults. I. Chronic persistent asthma. BMJ I990; 301: 651-653.

2. National Heart, Lung and Blood Institute, National Institute of Health, Bethesda, Maryland, USA. International consensus report on diagnosis and treatment of asthma. Eur Respir J 1992; 5: 601-641.

3. Warner JO, Neijens HJ, Landau LI, et al. Asthma: a follow-up statement from an international paediatric asthma consensus group. Arch Dis Child 1992; 67: 240-248.

4. Molema J, Van Herwaarden CLA, Folgering HTM. Effects of long-term treatment with inhaled cromoglycate and budesonide on bronchial hyperresponsiveness in patients with allergic asthma. Eur Respir J 1989; 2: 308-316.

5. Geddes DM. Inhaled corticosteroids: benefits and risks. Thorax 1992; 47: 404-407.
6. Warner JO, Reiser J. Inhaled glucocorticoids in childhood asthma. In: Godfrey S, eds. Glucocorticosteroids in Childhood Asthma, Exerpta Medica, Amsterdam, 1987; pp. 78-84.

7. Springer C, Avital A, Maayan CH, et al. Comparison of budesonide and beclomethasone dipropionate for treatment of asthma. Arch Dis Child 1987; 62(8): 815-819.

8. Baran D. A comparison of inhaled budesonide and beclomethasone dipropionate in childhood asthma. $\mathrm{Br}$ J Dis Chest 1987; 81(2): 170-175.

9. Brogden RN, McTavish D. Budesonide an updated review of its pharmacological properties and therapeutic efficacy in asthma and rhinitis. Drugs 1992; 44(3): 375-407.

10. Pedersen S, Fugslang G. Urine cortisol excretion in children treated with high doses of inhaled corticosteroids: a comparison of budesonide and beclomethasone. Eur Respir J 1988; 1: 433-435.

11. Field HV, Jenkinson PMA, Frame MH, et al. Asthma treatment with a new corticosteroid aerosol budesonide, administered twice daily by spacer inhaler. Arch Dis Child 1982; 57(11): 864-866.

12. Holliday SM, Faulds D, Sorkin EM. Inhaled fluticasone propionate: a review of its pharmacodynamic and pharmacokinetic properties, and therapeutic use in asthma. Drugs 1994; 47: 318-331.

13. Phillipps GH. Structure-activity relationships of topically active steroids: the selection of fluticasone propionate. Respir Med 1990; 84 (Suppl. A): 19-23.

14. Ryerfeldt $\AA$, Andersson P, Edsbäcker S, et al. Pharmacokinetics and metabolism of budesonide, a selective glucocorticoid. Eur J Respir Dis 1982; 63 (Suppl. 122): $86-95$.

15. Harding SM. The human pharmacology of fluticasone propionate. Respir Med 1990; 84 (Suppl. A): 25-29.

16. Gustafsson P, Tsanakas J, Gold M, Primhak R, Radford M, Gillies E. Comparison of the efficacy and safety of inhaled fluticasone propionate $200 \mu \mathrm{g} \cdot \mathrm{day}^{-1}$ with inhaled beclomethasone dipropionate $400 \mu \mathrm{g} \cdot \mathrm{day}^{-1}$ in mild and moderate asthma. Arch Dis Child 1993; 69: 206-211.

17. Lundback B, Dahl R, De Jonghe M, Hyldebrandt N, Valta R, Payne SL. A comparison of fluticasone propionate when delivered by either the metered-dose inhaler or the Diskhaler in the treatment of mild-to-moderate asthma. Eur J Clin Res 1994; 5: 11-19.

18. Lundback B, Alexander M, Day J, et al. Evaluation of fluticasone propionate $\left(500 \mu \mathrm{g} \cdot \mathrm{day}^{-1}\right)$ administered either as dry powder via a Diskhaler ${ }^{\circledR}$ inhaler or pressurized inhaler and compared with beclomethasone dipropionate $\left(1,000 \mu \mathrm{g} \cdot \mathrm{day}^{-1}\right)$ administered by pressurized inhaler. Respir Med 1993; 87: 609-620.

19. Agertoft L, Pedersen S. Importance of inhalation device on the effect of budesonide. Arch Dis Child 1993; 69: 130-133.

20. White FA, Toogood JH, Baskerville J, Hodsman A. A comparison of the efficacy and systemic effects of budesonide administered as an aerosol via metered-dose inhaler + Nebuhaler and as a dry powder via Turbuhaler [Abstract]. J Allergy Clin Immunol 1995; 95 (No. 1, part 2): 688.

21. Selroos O, Holme M. Effect of a Volumatic spacer and mouth rinsing on systemic absorption of inhaled corticosteroids from a metered dose inhaler and dry powder inhaler. Thorax 1991; 46: 891-894.

22. Brown PH, Lenney J, Armstrong S, et al. Breath-actuated inhalers in chronic asthma: comparison of Diskhaler and Turbohaler for delivery of beta-agonists. Eur Respir J 1992; 5: 1143-1145. 
23. Petrie GR, Choo-Kang YFS, Clark RA, et al. An assessment of the acceptability of two breath-actuated corticosteroid inhalers. comparison of Turbohaler and Diskhaler. Drug Invest 1990; 2(2): 129-131.

24. Harvey J, Williams JG. Randomised, cross-over comparison of five inhaler systems for bronchodilator therapy. Br J Clin Pract 1992; 46: 249-251.

25. Connolly A. A Comparison of fluticasone propionate, $100 \mu \mathrm{g}$ twice daily, with budesonide, $200 \mu \mathrm{g}$ twice daily via their respective powder devices in the treatment of mild asthma. Eur J Clin Res 1995; 7: 15-29.

26. Langdon CG, Capsey LJ. Fluticasone propionate and budesonide in adult asthmatics: a comparison using dry-powder inhaler devices. Br J Clin Res 1994; 5: 8599.

27. Ayres JG, Bateman ED, Luundback B, Harris TAJ. High dose fluticasone, $1 \mathrm{mg}$ daily, versus fluticasone propionate, $2 \mathrm{mg}$ daily, or budesonide, $1.6 \mathrm{mg}$ daily, in patients with chronic severe asthma. Eur Respir $J$ 1995; 8: 579-586.

28. Williams J. Efficacy and use of the fluticasone propionate multi-dose powder inhaler compared with the budesonide reservoir powder device in asthmatic children. Eur Respir J 1995; 8 (Suppl. 19): P2313.

29. Polgar G, Promhadhat V. Pulmonary function testing in children: techniques and standards. London, W.P. Saunders, 1971.

30. Conover JW. In: Practical Nonparametric Statistics. 2nd edn. New York, John Wiley and Sons, 1980; pp. 223-225.

31. Lehman EL. In: Nonparametrics: Statistical Methods Based on Ranks. San Francisco, Holden-Day Inc., 1995; p. 135.

32. Lenney W, Wells NEJ, O'Neill BA. The burden of paediatric asthma. Eur Resp Rev 1994; 4(18): 49-62.

33. Juniper EF, Johnston PR, Borkhoff CM, Guyatt GH, Boulet LP, Haukioja A. Quality of life in asthma: Comparison of salmeterol and salbutamol. Am J Respir Crit Care 1995; 151: 66-70.

34. Nicolaizik WH, Marchant JL, Preece MA, Warner JO. Endocrine and lung function in asthmatic children on inhaled corticosteroids. Am J Respir Crit Care Med 1994; 150: 624-628.
35. Priftis K, Milner AD, Conway E, Honour JW. Adrenal function in asthma. Arch Dis Child 1990; 65: 838-840.

36. Bisgaard H, Nielsen MD, Anderson B, et al. Adrenal function in children with bronchial asthma treated with beclomethasone dipropionate or budesonide. J Allergy Clin Immunol 1988; 81: 1088-1095.

37. Pedersen S, Fuglsang G. Urine cortisol excretion in children treated with high doses of inhaled corticosteroids: a comparison of budesonide and beclomethasone Eur Respir J 1988; 1: 433-435.

38. Mackenzie CA, Weinberg EG, Tabachnik E, Taylor M, Havnen J, Crescenzi K. A placebo-controlled trial of fluticasone propionate in asthmatic children. Eur $J$ Pediatr 1993; 152: 856-860.

39. Mackenzie CA, Tsanakas J, Tabachnik E, et al. An open study to assess the long-term safety of fluticasone propionate in asthmatic children. Br J Clin Prac 1994; 48: 15-18.

40. Sorva R, Turpeinen M, Juntunen-Backman K, Karonen S, Sorva A. Effects of inhaled budesonide on serum markers of bone metabolism in children with asthma. J Allergy Clin Immunol 1992; 90: 808-815.

41. Priftis K, Voskaki I, Papadimitriou A, et al. Effects of long term treatment with inhaled steroids on bone metabolism in asthmatic children. Eur Respir J 1994; 7 (Suppl. 18): 285.

42. Doull JM, White M, Freezer NJ, Holgate ST. Markers of bone metabolism in asthmatic children receiving inhaled corticosteroids. Eur Respir J 1994; 7 (Suppl. 18): 285.

43. Konig P, Hillman L, Cervantes C, et al. Bone metabolism in children with asthma treated with inhaled beclomethasone dipropionate. J Pediatr 1993; 122: 219-226.

44. Wolthers O, Pedersen S. Measures of systemic activty of inhaled glucocorticoids in children: a comparison of urine cortisol and knemometry. Respir Med 1995; 89: 347-349.

45. Agertoft L, Pedersen S. Short-term lower leg growth in children during treatment with fluticasone propionate and budesonide: a dose response study. Am J Respir Crit Care Med 1995; 151(4): A150. 